\title{
Arterial Blood Levels of Energy Substrates and Evidence for Renal Glucose Production in the Baboon Infant
}

\author{
LYNNE L. LEVITSKY, ${ }^{(3)}$ JOHN B. PATON, DAVID E. FISHER, AND CLARENCE W. DELANNOY \\ Departments of Pediatrics [L. L. L., J. B. P., D. E. F.] and Laboratory Animal Medicine [C. W. D.], Michael Reese \\ Hospital and Medical Center, Pritzker School of Medicine, University of Chicago, Chicago, Illinois, USA
}

\begin{abstract}
Summary
The age-related changes in fasting arterial levels of energy substrates and insulin were studied at birth and/or 6 wk in eleven baboon infants. In addition, the renal contribution to glucose release in the primate infant was estimated. Arterial blood glucose levels were similar in six fasted newborns and in nine fasted 6-wkold infants. Arterial blood lactate, alanine, pyruvate, glutamate, and glutamine levels were significantly higher $(P<0.01)$ in the new born animals, and $\beta$-hydroxybutyrate was significantly higher in the older animals $(P<0.001)$. Arterial plasma insulin levels were low in both groups. Levels of blood glucose in the inferior vena cava below the renal vein were significantly lower than levels in the aorta $(P<0.01)$. In contrast, levels of blood glucose in the inferior vena cava above the renal vein were significantly higher than in the aorta $(P<0.05)$. Computed renal vein glucose levels were higher than those in the aorta $(P<0.01)$. In the newborn infants, there was significant renal uptake of lactate, pyruvate, glycerol, and glutamine $(P<0.01)$, and release of $\beta$-hydroxybutyrate $(P<0.05)$. In the older animals, there was renal uptake of alanine, lactate, pyruvate, and glycerol $(P$ 0.01). Mean cardiac output per $\mathrm{kg}$ body weight did not differ significantly in the newborn and 6-wk-old infants.

Lactate uptake was potentially responsible for $59 \%$ of mean renal glucose output in the newborn and $76 \%$ of mean renal glucose output in the older infant. Net renal glucose release in eight 6-wkold infants was estimated to be $3.5 \pm 1.1 \mu \mathrm{M} / \mathrm{min} \cdot \mathrm{kg}(95 \%$ confidence limits, $0.7<3.5<6.2$ ). Net renal glucose release in three newborn infants was $4.7,5.4$, and $19.8 \mu \mathrm{M} / \mathrm{min} \cdot \mathrm{kg}$. There was a significant linear relationship between arterial lactate levels and renal glucose production in the older infants $(P<0.05)$. Extremely low arterial $\mathrm{pH}$ was associated with increased renal glucose release in the newborn, and high arterial $\mathrm{pH}$ with decreased or absent glucose release in the 6-wk-old animals.
\end{abstract}

\section{Speculation}

The primate infant kidney has a capacity for gluconeogenesis which is apparently enhanced by acidosis and lactate availability. In the stressed human neonate, it is possible that renal gluconeogenesis could be a significant and uncontrolled source of new glucose, leading to hyperglycemia.

The renal contribution to gluconeogenesis is significant in fasting man and in lower mammalian species $(14,23)$. However, the role of renal glucose production in energy metabolism in the young animal has not been well studied. Most information concerning gluconeogenesis in infancy has been derived from studies in the rat. Gluconeogenesis in developing rat kidney cortex may be identified in late fetal life (30). In contrast, the ability to adapt to fasting by increased hepatic gluconeogenesis is acquired postnatally in this species (10). The relative contribution of the kidneys to glucose production in the young of higher mammalian species and the primate neonate and infant, in particular, is unknown.

To investigate the renal contribution to glucose release in the primate infant, we have used a baboon model which has previously been determined to resemble the stressed, low-birth-weight infant in its metabolic responses (18). In addition, we have further characterized the age-related changes in fasting arterial levels of energy substrates and insulin in this model.

\section{METHODS}

Eleven baboon infants were studied. Infants were the products of timed matings. Six baboon neonates were delivered by cesarean section at term after a gestation of $173 \pm 1$ days and studied at 6 to $8 \mathrm{hr}$ of life. Four of these animals (gestational age, $172 \pm 1$ days) were then maintained in infant incubators and fed commercial infant formula until studied again at 6 wk of life. Four other baboon neonates, products of spontaneous deliveries at $173 \pm 8$ days gestation, were maintained in a similar fashion and studied for the first time at $6 \mathrm{wk}$. One animal, delivered by cesarean section at 168 days, was successfully studied for the first time at 6 wk. The mean body weight of the newborn animals was $771 \pm 34$ $\mathrm{g}$, and the mean body weight of the 6-wk-old animals was 1110 $\pm 40 \mathrm{~g}$. Mean renal weight obtained at termination of each study was $7.6 \pm 4 \mathrm{~g}$ at $6 \mathrm{wk}$.

With local xylocaine anesthesia, catheters (PV3-Biolabs) were placed in the aorta, the left ventricular outflow tract, and the inferior vena cava above and below the level of the renal veins (Fig. 1). Positioning was assessed radiographically and reassessed at autopsy in terminal studies. Renal vein catheterization has not proved technically feasible in this preparation. Animals were maintained under a radiant warmer during procedures and restrained but not sedated. Newborns were fasted from birth; animals studied at $6 \mathrm{wk}$ were fasted for $20 \mathrm{hr}$. Stability was assessed by regular monitoring of arterial blood $\mathrm{pH}$ and $\mathrm{PO}_{2}$.

Studies were carried out 2 to $4 \mathrm{hr}$ following catheter placement. Seven to eight simultaneous one-ml samples were obtained from the aorta $(A)$ and from the inferior vena cava above $\left(V_{2}\right)$ and below $\left(V_{1}\right)$ the renal vein. Samples were obtained at 15-min intervals. Blood was replaced volume for volume with placental or maternal blood in all infants.

Blood and urine samples were analyzed for glucose (29), glycerol (17), lactate (20), pyruvate (13), alanine (13), glutamate (6), glutamine (6), and $D-\beta$-hydroxybutyrate (25) using enzymatic fluorometric methods. Urine samples were obtained by bladder catheterization. Samples were analyzed immediately or frozen at $-70^{\circ} \mathrm{C}$ until analysis. All analyses were performed in duplicate, but not all substrate analyses were performed on each specimen. Blood gas determinations were performed using Radiometer electrodes and meter PHM 71. Arterial plasma samples were analyzed for insulin by double antibody radioimmunoassay (22). Microspheres labeled with different radioisotopes were used to assess renal blood flow in duplicate during each study. Animals were 
ESTIMATION OF RENAL SUBSTRATE ARTERIOVENOUS DIFFERENCES

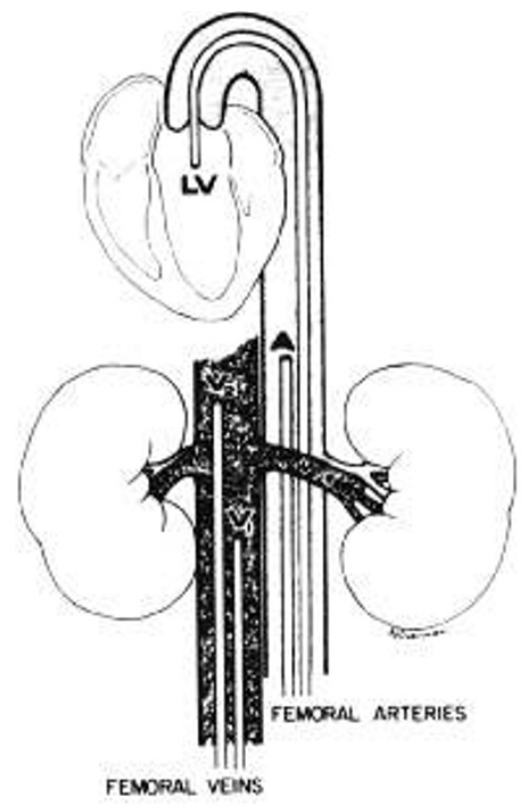

Fig. 1. Diagrammatic representation of catheter placement for estimation of renal vein substrate concentration. $L V$, left ventricular outflow tract; $A$, aorta; $V_{1}$, inferior vena cava below renal veins; $V_{2}$, inferior vena cava above renal veins.

dissected, and organs were completely ashed. The content of each radioisotope was measured in a multichannel automatic gamma counter. Cardiac output was assessed by timed withdrawal of blood following injection of microspheres (24). These data were used to compute true or relative organ blood flows and thereby estimate renal vein concentration of substrates. The following formula was used to derive estimates of renal vein concentrations (RV), based upon determinations of inferior vena cava blood flow below the renal vein $\left(F_{L C}\right)$, renal blood flow $\left(F_{R}\right)$, and substrate concentrations in the inferior vena cava above $\left(V_{2}\right)$ and below $\left(V_{1}\right)$ the renal vein

$$
[R V]=\frac{\left[V_{2}\right]\left(F_{L C}+F_{R}\right)-\left[V_{1}\right]\left(F_{1, C}\right)}{F_{R}}
$$

Mean arterial and venous blood substrate levels at different ages were compared using the two-tailed Student $t$ test. Renal substrate uptake and release was examined by one-way analysis of variance. No correction was made for urinary losses because urine flow was less than $0.5 \%$ of renal blood flow, and urine concentrations of those substrates taken up by the kidney were negligible.

Four to six simultaneous determinations for each substrate and one or two blood flow determinations were obtained for each animal. Estimates of renal vein concentration for each animal were the means of separate computations for each set of simultaneous samples $\left(A, V_{1}\right.$, and $\left.V_{2}\right)$.

\section{MATERIALS}

Baboon infants were obtained from the University of Illinois Primate Colony (Chicago, IL). Enzymes for substrate analysis were obtained from Boehringer-Mannheim, New York, NY (glycerokinase, glycerophosphate dehydrogenase, and glutamate dehydrogenase), and Sigma Chemical Co., St. Louis, MO (lactic dehydrogenase, $D$ - $\beta$-hydroxybutyrate dehydrogenase, glutamicpyruvic transaminase, and glutaminase). Reagents used to construct standard curves were purchased from Sigma Chemical Co. (lactic acid, D- $\beta$-hydroxybutyrate, $\alpha$-ketoglutarate, alanine, pyruvate, and glutamate) and Sargent-Welch, Chicago, IL (glycerol).
NADH and NAD were purchased from Sigma Chemical Co. Fluorometric analyses were performed on an Aminco-Bowman SPF-125 spectrophotofluorometer. Radioiodinated insulin was obtained from Abbott Laboratories. Human insulin standards (a gift of Dr. Mary Root, Eli Lilly Research Laboratories) were used for radioimmunoassays. Radioactive microspheres were obtained from 3M Co., St. Paul, MN.

\section{RESULTS}

\section{FASTING ARTERIAL AND VENOUS BLOOD SUBSTRATE LEVELS AND INSULIN RESPONSE TO FASTING}

Arterial blood glucose levels were similar in the 6-to 8-hr fasted newborns and the 20-hr-fasted 6-wk-old baboon infants. However, arterial blood lactate, alanine, pyruvate, glutamate, and glutamine levels were significantly higher $(P<0.01)$ in the newborn animals, and $\beta$-hydroxybutyrate was significantly higher in the older animals $(P<0.001)$. Substrate values in the inferior vena cava above and below the renal veins varied similarly in the two age groups (Table 1). Mean arterial plasma insulin levels were $3.7 \pm 0.5 \mu \mathrm{U}$ / $\mathrm{ml}$ at birth and $2.5 \pm 0.4 \mu \mathrm{U} / \mathrm{ml}$ at $6 \mathrm{wk}$.

\section{EVIDENCE FOR RENAL SUBSTRATE RELEASE AND UPTAKE}

If one inspects mean blood glucose levels in the aorta and in the vena cava above and below the renal veins in each animal studied, it is evident that in all newborn animals (Fig. 2) and in 8 of 9 older infants (Fig. 3) blood glucose levels in the inferior vena cava above the renal veins were equal to or higher than levels in the aorta, implying net renal glucose release. The standard error of the mean for five replicated samples is displayed in these figures. These standard errors, therefore, do not represent the variation in each comparable set of blood samples. For this reason, further statistical analysis is necessary to appreciate these differences. Examination of the data by one-way analysis of variance substantiates the visual impression. Levels of blood glucose in the inferior vena cava below the renal vein were significantly lower than levels in the aorta $(P<0.01)$. In contrast, levels of blood glucose in the inferior vena cava above the renal vein were signifcantly higher than those in the aorta $(P<0.05)$, suggesting that there was a measurable contribution of glucose from the renal vein. Computed renal vein glucose levels were significantly higher than arterial levels $(P<0.01$ newborn and older animals). In addition, as described in Table 1 , significant substrate uptake was identified for lactate, pyruvate, glycerol, and glutamine in the newborn infants $(P<0.01)$ using one-way analysis of variance. In these infants, there was no evidence for glutamate or alanine uptake and $\beta$-hydroxybutyrate was apparently released by the kidney $(P<0.05)$. In contrast, the older animals manifested significant renal uptake of alanine as well as lactate, pyruvate, and glycerol $(P<0.01)$. Neither glutamate nor glutamine was taken up, and $\beta$-hydroxybutyrate was neither taken up nor released.

\section{CARIDAC OUTPUT, RENAL BLOOD FLOW, AND LOWER CARCASS BLOOD FLOW}

To estimate renal vein substrate concentrations, determinations of cardiac output and regional blood flow were obtained using the radioactive microsphere technique. As displayed in Table 2, mean cardiac output successfully obtained in four newborn and eight 6wk-old infants was not significantly different when adjusted for body weight.

Renal blood flow seemed to be greater in the older animals. Similarly, lower carcass blood flow designated as blood flow below the level of the renal vessels was also greater in the older animals. Statistical analysis of these observations was not possible because there were only three animals with absolute renal blood flow determinations in the newborn group. Comparison of blood flow per $\mathrm{kg}$ renal tissue was not possible because newborn animals were not immediately sacrificed. 
Table 1. Blood levels in $\mathrm{mM}$ (mean \pm S.E.) of glucose and other substrates in the aorta, the inferior vena cava below and above the renal veins, the renal vein. ${ }^{1}$ and renal venoarterial differences for these substrates

\begin{tabular}{|c|c|c|c|c|c|}
\hline & $A^{2}$ & $v_{1}$ & $\mathrm{v}_{2}$ & RV & RV-A \\
\hline \multicolumn{6}{|l|}{ Newborn $(n=6)$} \\
\hline Glucose & $2.06 \pm 0.11$ & $1.80 \pm 0.18$ & $2.22 \pm 0.17$ & $3.70 \pm 0.39$ & $1.67 \pm 0.42$ \\
\hline Lactate & $3.24 \pm 0.34$ & $4.22 \pm 0.32$ & $3.30 \pm 0.50$ & $1.28 \pm 0.50$ & $-1.96 \pm 0.35$ \\
\hline Pyruvate & $0.154 \pm 0.031$ & $0.156 \pm 0.031$ & $0.143 \pm 0.033$ & $0.115 \pm 0.036$ & $-0.034 \pm 0.020$ \\
\hline Alanine & $0.327 \pm 0.028$ & $0.346 \pm 0.019$ & $0.325 \pm 0.021$ & $0.265 \pm 0.052$ & $-0.068 \pm 0.040$ \\
\hline$\beta$-Hydroxybutyrate & $0.15 \pm 0.02$ & $0.13 \pm 0.02$ & $0.14 \pm 0.02$ & $0.19 \pm 0.04$ & $0.04 \pm 0.02$ \\
\hline Glycerol & $0.37 \pm 0.03$ & $0.40 \pm 0.03$ & $0.32 \pm 0.03$ & $0.16 \pm 0.07$ & $-0.22 \pm 0.03$ \\
\hline Glutamine & $0.37 \pm 0.04$ & $0.40 \pm 0.05$ & $0.32 \pm 0.03$ & $0.17 \pm 0.05$ & $-0.14 \pm 0.07$ \\
\hline Glutamate & $0.58 \pm 0.07$ & $0.55 \pm 0.07$ & $0.57 \pm 0.06$ & $0.62 \pm 0.12$ & $0.06 \pm 0.07$ \\
\hline
\end{tabular}

4-6 wk $(n=9)$

$\begin{array}{lc}\text { Glucose } & 2.23 \pm 0.19 \\ \text { Lactate } & 1.14 \pm 0.07 \\ \text { Pyruvate } & 0.063 \pm 0.006 \\ \text { Alanine } & 0.128 \pm 0.008 \\ \beta \text {-Hydroxybutyrate } & 3.42 \pm 0.53 \\ \text { Glycerol } & 0.25 \pm 0.03 \\ \text { Glutamine } & 0.17 \pm 0.02 \\ \text { Glutamate } & 0.32 \pm 0.02\end{array}$

$$
\begin{aligned}
2.09 & \pm 0.20 \\
1.68 & \pm 0.16 \\
0.077 & \pm 0.008 \\
0.170 & \pm 0.012 \\
3.45 & \pm 0.55 \\
0.35 & \pm 0.02 \\
0.21 & \pm 0.03 \\
0.30 & \pm 0.02
\end{aligned}
$$

$$
\begin{gathered}
2.25 \pm 0.18 \\
1.29 \pm 0.08 \\
0.067 \pm 0.006 \\
0.141 \pm 0.012 \\
3.40 \pm 0.52 \\
0.30 \pm 0.04 \\
0.18 \pm 0.02 \\
0.30 \pm 0.02
\end{gathered}
$$

$$
\begin{gathered}
2.47 \pm 0.20 \\
0.86 \pm 0.14 \\
0.057 \pm 0.008 \\
0.108 \pm 0.016 \\
3.41 \pm 0.55 \\
0.19 \pm 0.08 \\
0.15 \pm 0.02 \\
0.30 \pm 0.03
\end{gathered}
$$

\begin{tabular}{|c|c|c|c|c|}
\hline & $\begin{array}{c}\text { Cardiac } \\
\text { output } \\
\text { (ml/min) }\end{array}$ & $\begin{array}{c}\text { Cardiac } \\
\text { output } / \mathrm{kg} \\
\text { (ml/min. } \\
\left.\mathrm{kg}^{-1}\right)\end{array}$ & $\begin{array}{c}\text { Renal } \\
\text { blood } \\
\text { flow } \\
(\mathrm{ml} / \mathrm{min})\end{array}$ & $\begin{array}{c}\text { Lower } \\
\text { carcass } \\
\text { blood } \\
\text { flow } \\
\text { (ml/min) }\end{array}$ \\
\hline $\begin{array}{r}\text { Newborn } \\
(n=4)\end{array}$ & $128 \pm 24^{\prime}$ & $188 \pm 36$ & $2.6 \pm 0.6^{2}$ & $14 \pm 4^{2}$ \\
\hline $\begin{array}{l}6 \mathrm{wk} \\
\quad(n=8)\end{array}$ & $168 \pm 11$ & $156 \pm 8$ & $14 \pm 1$ & $18 \pm 2$ \\
\hline
\end{tabular}$$
\begin{aligned}
0.21 & \pm 0.08 \\
-0.32 & \pm 0.14 \\
-0.006 & \pm 0.008 \\
-0.025 & \pm 0.011 \\
-0.01 & \pm 0.05 \\
0.05 & \pm 0.08 \\
-0.03 & \pm 0.01 \\
0.01 & \pm 0.02
\end{aligned}
$$

' Renal vein substrate levels are calculated using absolute renal and lower carcass flow determinations or relative renal:lower carcass blood flow ratios when cardiac output determinations are not available. All other levels are based upon direct measurement.

${ }^{2} A$, aorta. $V_{1}$, inferior vena cava below renal veins; $V_{2}$, inferior vena cava above renal veins; $R V$, renal vein; $R V-A$, renal venoarterial.

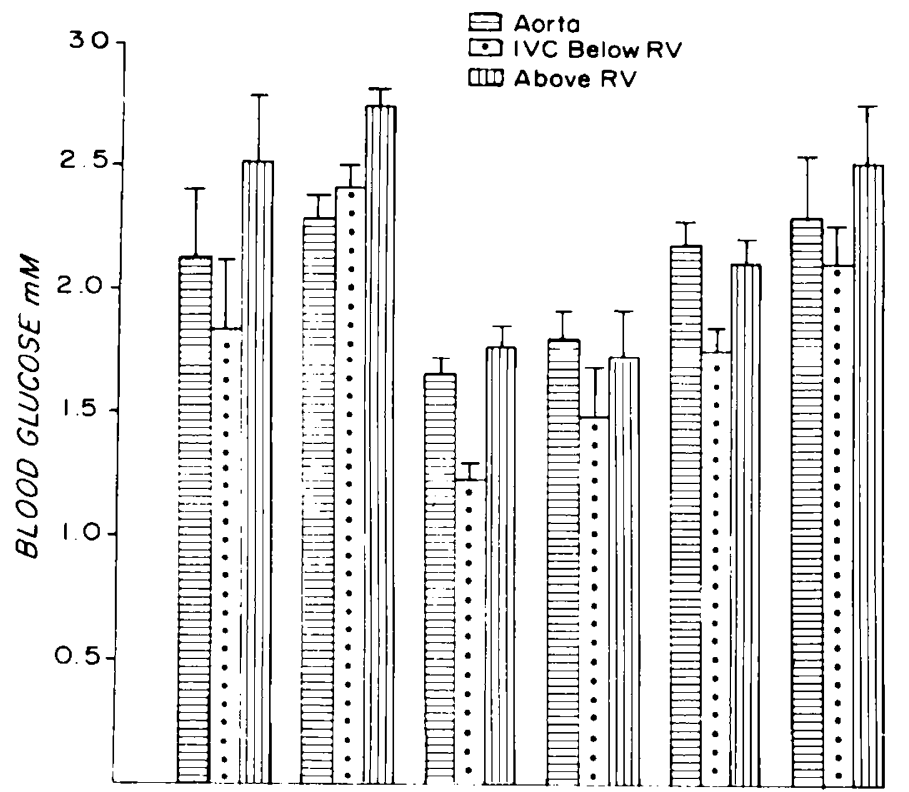

Fig. 2. Blood glucose concentrations in the aorta, the inferior vena cava below the renal vein $(I V C$ below $R V$ ), and the inferior vena cava above the renal vein (above $R V$ ) in six baboon neonates after a 6- to 8-hr fast. Bars, mean ( \pm S.E.) of five separate determinations in each animal.

\section{RENAL VENOARTERIAL DIFFERENCES FOR GLUCOSE COMPARED TO} THOSE FOR POTENTIAL GLUCOSE PRECURSORS

Table 3 compares the renal release of glucose with the potential maximal gluconeogenic equivalents generated by lactate, pyruvate, glycerol, alanine, and glutamine, expressed as venoarterial differences. Lactate uptake in gluconeogenic equivalents could be responsible for $59 \%$ of mean renal glucose output in the newborn and $76 \%$ of glucose output in the older animals. Other substrates potentially play a much less significant role. Of note, glycerol uptake was considerable in the newborn baboon but was irregular in the older animal. Arterial glycerol levels, as noted previously, were also significantly higher in the neonate.
Table 2. Cardiac output, renal blood flow, and lower carcass blood flow in newborn and 6-wk-old baboon infants

\section{RENAL GLUCOSE RELEASE}

Renal glucose release was estimated using renal blood flow and computed arteriovenous differences for glucose (Table 4). Estimated net renal glucose release in the 6-wk-old infant was $3.6 \pm$ $1.2 \mu \mathrm{M} / \mathrm{min}(95 \%$ confidence limits, $0.8<3.6<6.3)$, or $3.5 \pm 1.1$ $\mu \mathrm{M} / \mathrm{min} \cdot \mathrm{kg}(95 \%$ confidence limits, $0.7<3.5<6.2)$. Only three animals had absolute renal blood flow determinations in the newborn period. These animals had glucose release rates of 2.1 , 4.6 , and $12.9 \mu \mathrm{M} / \mathrm{min}$ or adjusted rates of $4.7,5.4$, and $19.8 \mu \mathrm{M}$ / $\mathrm{min} \cdot \mathrm{kg}$.

In the seven 6-wk-old infants whose kidneys released glucose, there was a significant $(P<0.05)$ linear relationship between arterial lactate levels and renal glucose production (Fig. 4 ). This relationship remained significant $(P<0.05)$ even if examined as a function of body weight. No such relationship was identified between glucose production and arterial levels of other substrates including glycerol, glutamine, glutamate, and pyruvate. Although no statistically significantly relationship could be established between arterial $\mathrm{pH}$ and renal glucose release, it is noteworthy that the 6-wk-old animals with arterial $\mathrm{pH}$ above 7.40 were animal 8 , whose kidney seemed to take up glucose, and animal 1, which had the lowest $(0.68 \mu \mathrm{M} / \mathrm{min} \cdot \mathrm{kg})$ glucose production rate. In addition, the animal with the lowest arterial $\mathrm{pH}$ (newborn animal 1) had the highest glucose production rate. 


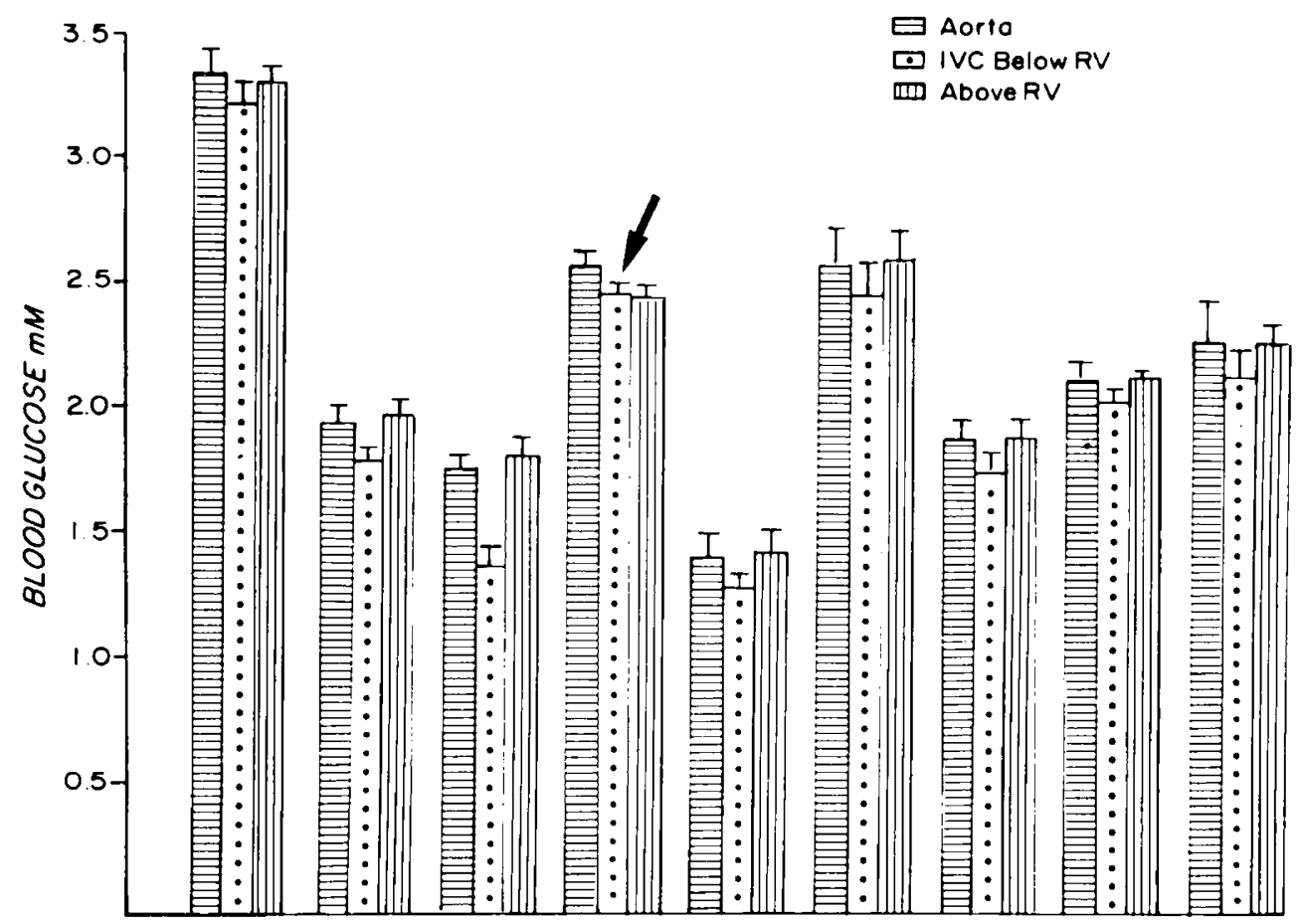

Fig. 3. Blood glucose concentrations in the aorta, the inferior vena cava below the renal vein, and the inferior vena cava above the renal vein in nine 6-wk-old baboon infants after a 20-hr fast. Bars, mean ( \pm S.E.) of five separate determinations in each animal. The animal identified with an arrow does not display renal glucose release. Abbreviations as in Figure 2.

Table 3. Renal venoarterial differences for glucose and maximal glucose equivalents of gluconeogenic substrates taken up by the kidney

\begin{tabular}{|c|c|c|c|c|c|c|c|}
\hline & \multicolumn{5}{|c|}{ Renal venoarterial glucose equivalents } & \multirow{2}{*}{$\begin{array}{c}\text { Total } \\
\text { glucose } \\
\text { equivalents }\end{array}$} & \multirow{2}{*}{$\begin{array}{c}\text { Renal } \\
\text { venoarterial } \\
\text { glucose }\end{array}$} \\
\hline & Lactate & Pyruvate & Glycerol & Alanine & Glutamine' & & \\
\hline Newborn & $0.98 \pm 0.18^{2}$ & $0.017 \pm 0.010$ & $0.11 \pm \underset{-3}{0.015}$ & $\begin{array}{l}0.034 \pm 0.02 \\
0.012 \pm 0.006\end{array}$ & $\begin{array}{r}0.07 \pm 0.035 \\
0.015 \pm 0.005\end{array}$ & $\begin{array}{l}1.21 \pm 0.26 \\
0.19 \pm 0.085\end{array}$ & $\begin{array}{l}1.67 \pm 0.42 \\
0.21 \pm 0.08\end{array}$ \\
\hline
\end{tabular}

${ }^{1}$ All substrates, including glutamine, are assumed to be utilized as 3-carbon precursors of glucose.

${ }^{2} \mathrm{mM} \pm$ S.D.

${ }^{3}$ One animal did not display glycerol uptake, large S.E. precludes inclusion of glycerol.

Table 4. Estimated renal glucose release based upon venoarterial differences for glucose and renal blood flow: comparison to arterial lactate and $\mathrm{pH}$

\begin{tabular}{|c|c|c|c|c|c|c|c|c|}
\hline & & $\begin{array}{c}\text { Renal } \\
\text { venoarterial } \\
(\mathrm{mM})\end{array}$ & $\begin{array}{c}\text { Renal } \\
\text { blood } \\
\text { flow } \\
(\mathrm{ml} / \mathrm{min})\end{array}$ & $\begin{array}{c}\text { Renal } \\
\text { glucose } \\
\text { release } \\
(\mu \mathrm{M} / \mathrm{min})\end{array}$ & $\begin{array}{c}\text { Renal } \\
\text { blood } \\
\text { flow } \\
(\mathrm{ml} / \mathrm{min} \cdot \mathrm{kg})\end{array}$ & $\begin{array}{c}\text { Renal } \\
\text { glucose } \\
\text { release } \\
(\mu \mathrm{M} / \mathrm{min} \cdot \mathrm{kg})\end{array}$ & $\begin{array}{c}\text { Arterial } \\
\text { lactate } \\
(\mathrm{mM})\end{array}$ & $\begin{array}{c}\text { Arterial } \\
\mathrm{pH}\end{array}$ \\
\hline \multirow[t]{3}{*}{ Newborn } & 1 & 3.42 & 3.76 & 12.86 & 5.78 & 19.77 & 2.24 & 7.30 \\
\hline & 2 & 1.16 & 1.83 & 2.12 & 4.02 & 4.66 & 2.10 & 7.38 \\
\hline & 3 & 2.09 & 2.21 & 4.62 & 2.57 & 5.37 & 3.54 & 7.46 \\
\hline Mean & & $\ldots$ & - & - & - & - & - & - \\
\hline S.E. & & - & - & - & - & - & - & - \\
\hline \multirow[t]{8}{*}{$6 \mathrm{wk}$} & 1 & 0.06 & 13.53 & 0.81 & 11.28 & 0.68 & 1.02 & 7.48 \\
\hline & 2 & 0.42 & 20.68 & 8.69 & 15.91 & 6.68 & 1.42 & 7.39 \\
\hline & 3 & 0.61 & 12.39 & 7.56 & 14.57 & 8.89 & 1.36 & 7.37 \\
\hline & 4 & 0.22 & 15.91 & 3.50 & 15.91 & 3.50 & 1.19 & 7.37 \\
\hline & 5 & 0.44 & 11.15 & 4.90 & 11.80 & 5.19 & 1.08 & 7.37 \\
\hline & 6 & 0.16 & 15.49 & 2.48 & 12.39 & 1.98 & 0.73 & 7.36 \\
\hline & 7 & 0.14 & 9.58 & 1.34 & 9.04 & 1.26 & 0.98 & 7.34 \\
\hline & 8 & -0.04 & 15.92 & -0.54 & 15.48 & -0.54 & 1.33 & 7.42 \\
\hline Mean & & 0.25 & 14.33 & 3.58 & 13.30 & 3.45 & 1.14 & 7.39 \\
\hline S.E. & & \pm 0.08 & \pm 1.22 & \pm 1.16 & \pm 0.90 & \pm 1.15 & \pm 0.08 & \pm 0.02 \\
\hline
\end{tabular}

\section{DISCUSSION}

In 1937, Benoy and Elliott (4) first identified that the kidney could synthesize glucose. Later workers amplified these initial studies, and both quantified renal cortex glucose production and elucidated its regulation. It is apparent that renal gluconeogenesis is substrate dependent $(7,21)$ and that under physiologic conditions, it usually appears linked to ammoniagenesis $(27,28)$. Renal gluconeogenesis in most species, although not all, seems enhanced by acidosis and by prolonged starvation $(11,16)$. Both acidosis and starvation increase activity of phosphoenolpyruvate carboxykinase so that glucose production from precursors such as lactate 


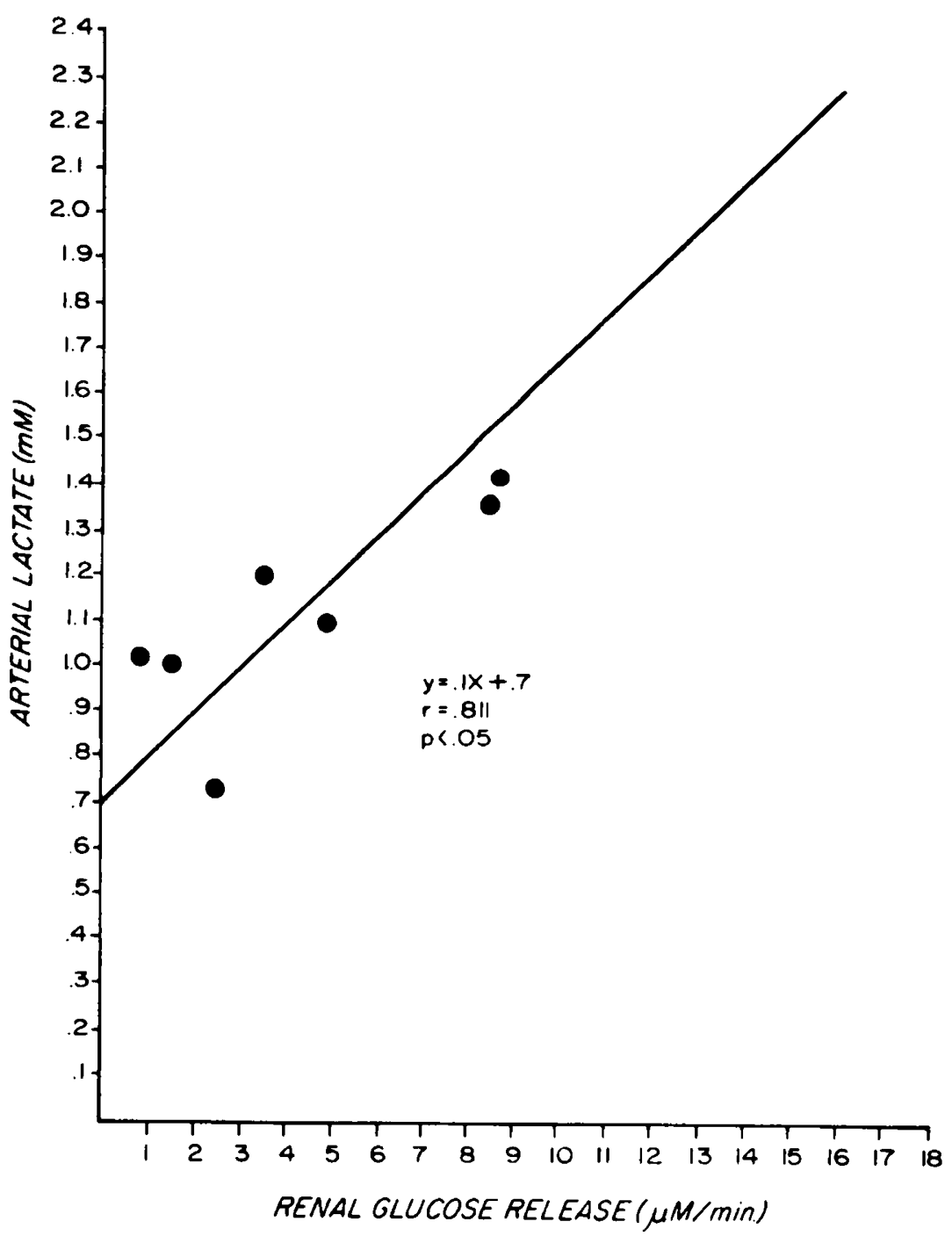

Fig. 4. The relationship between renal glucose release $(\mu \mathrm{M} / \mathrm{min})$ and arterial lactate $(\mathrm{mM})$ in seven 6-wk-old baboon infants displaying net renal glucose release.

which enter the gluconeogenic pathway below this enzyme increases (26). Indeed, studies in man would suggest that the kidney may supply up to $50 \%$ of new glucose in the long-term fasting state (23). Further, in the human kidney, an arterial pH above 7.4 is associated with markedly decreased net glucose release (1).

Other studies, using the isolated kidney and whole animal preparations, have determined that after a short-term fast the kidney takes up glucose, whereas free fatty acids and ketone bodies become a major energy source after longer fasting. When the kidney is in the fasting, acidotic gluconeogenic mode, major glucose precursors appear to be lactate, glutamine, glycerol, pyruvate, and to a lesser extent, alanine $(5,15,19)$. Citrate, not measured in this investigation, may also be an important gluconeogenic precursor (21). At least lactate appears to stimulate gluconeogenesis by its availability as a precursor (7). Information about renal gluconeogenesis in the neonate is scanty. Studies in lower mammals would suggest that both glucose-6-phosphatase and phosphoenolpyruvate carboxykinase activity is present at birth, but that activity increases, depending upon the species, either immediately following or within several wk after birth $(8$, 30). This would suggest a postnatal maturation of the renal gluconeogenic mechanism in these species similar to that seen in the liver. No such data are available in primates. Primate liver, on the other hand, seems to have the potential for gluconeogenesis and glycogenolysis before birth $(2,9)$. If the renal pattern of enzymatic maturation is similar to the hepatic pattern in primates, the acidotic, precursor-rich state often found in the stressed human neonate would seem to favor the renal contribution to new glucose formation. Data obtained in the human neonate using heavy isotope mass spectroscopic techniques suggest that in the basal state, total glucose turnover is approximately $25 \mu \mathrm{M} / \mathrm{min} \cdot \mathrm{kg}$ (12). Data for fasting neonates are not yet available. If glucose turnover rates in the subhuman primate infant are similar, the renal contribution to whole-body glucose production could, in some stressed neonates, be considerable.

We have identified that the levels of blood substrates found in the fasting state at birth and 6 wk of age in the baboon infant are similar to those found in the stressed human neonate and older infant (18). In addition, we have developed evidence that the infant baboon kidney is capable of releasing glucose and taking up a variety of gluconeogenic precursors, including lactate. Interestingly, we could not identify net uptake of $\beta$-hydroxybutyrate. Inasmuch as neither acetoacetate nor free fatty acids were measured in this study, and there is substantial exchange among these compounds, it is likely that $\beta$-hydroxybutyrate uptake was obscured by metabolic interconversion. Lactate seems to be the most important precursor taken up by the infant kidney. This may be secondary to the previously described relationship between lactate uptake and gluconeogenesis. In addition, we may infer that alkalosis inhibits renal gluconeogenesis, at least in the older baboon infant.

Renal gluconeogenesis has previously been reported to play a 
role in maintenance of blood glucose in experimental hypovolemic shock (3). If these findings are applicable to the human infant, then they would suggest that the stressed, acidotic human neonate with high lactate levels would be most likely to have significant renal glucose production. Based upon data available from the adult, such glucose production would not be totally subject to hormonal control by insulin and glucagon. It is possible that such renal gluconeogenesis could contribute to the hyperglycemia seen in some similarly stressed human infants.

\section{REFERENCES AND NOTES}

1. Aber, G. M., Morris, L. O., and Houseley, E.: Gluconeogenesis by the human kidney. Nature (Lond.), 212: 1589 (1966).

2. Adam, P. A. J., Glazer, C., Rogoff, F., Schwartz, A. L., Rahiala, E-L., and Kekomaki, M.: Autoregulation and evolution of glucagon control of hepatic glucose production in the human fetus and canine newborn. Clin. Res., 20: 539 (1972).

3. Archer, L. T., Benjamin, B., Lane, M. M., and Hinshaw, L. B.: Renal gluconeogenesis and increased glucose utilization in shock. Am. J. Physiol., 231: 872 (1976).

4. Benoy, M. P., and Elliott, K. A. C.: The metabolism of lactic and pyruvic acids in normal and tumor tissue. V. Synthesis of carbohydrate. Biochem. J., 3I: 1268 (1937)

5. Bergman, E. N., Kaufman, C. F., Wolf,, J. E., and Williams, H. H.: Renal metabolism of amino acids and ammonia in fed and fasted pregnant sheep. Am. J. Physiol., 221: 833 (1974).

6. Bernt, E., and Bergmeyer, H.: Methods in Enzymatic Analysis. p. 384 (Academic Press, Inc., New York, 1963)

7. Cohen, J. J., and Little, J. R.: Lactate metabolism in the isolated perfused rat kidney: relations to renal function and gluconeogenesis. J. Physiol. (Lond.), 225: 399 (1976).

8. Dawkins, M. J. R.: Changes in glucose-6-phosphatase activity in liver and kidney at birth. Nature (Lond.), 191: 72 (1961)

9. Gennser, G., Lundquist, I., and Nilsson, E.: Glycogenolytic activity in the liver of the human foetus. Biol. Neonate, 19: 1 (1971).

10. Girard, J. R., Cuendet, G. S., Marliss, E. B., Kervran, A., Rieutort, M., and Assan, R.: Fuels, hormones, and liver metabolism at term and during the early postnatal period in the rat. J. Clin. Invest., 52: 3190 (1973)

11. Jonsson, A., and Madison, L. L.: Evidence that the kidneys become a source of glucose for other tissues after fourteen days of starvation. Diabetes, Suppl. I, 17: 305 (1968).

12. Kalhan, S. C., Bier, D. M., Savin, S. M., and Adam, P. A. J.: Estimation of glucose production in the human newborn using simultaneous ${ }^{13} \mathrm{C}$ and $\mathrm{D}$ labelled glucose. Pediatr. Res., 12: 508 (1978).

13. Karl, I. E., Pagliara, A. S., and Kipnis, D. M.: A microfluorometric enzymatic assay for the determination of alanine and pyruvate in plasma and tissue. $J$. Lab. Clin. Med., 80: 434 (1972).

14. Kaufman, C. F., and Bergman, E. N.: Renal glucose, free fatty acid, and ketone body metabolism in the unanesthetized sheep. Am. J. Physiol., 221: 967 (1971).

15. Kaufman, C. F., and Bergman, E. N.: Renal ketone body metabolism and gluconeogenesis in normal and hypoglycemic sheep. Am. J. Physiol., 226: 827 (1974).

16. Kida, K., Shinjiro, N., Fumitada, K., Toyama, Y., Nishio, T., and Nakagawa, H.: Renal net glucose release in vivo and its contribution to blood glucose in rats. J. Clin. Invest. 62: 721 (1978).

17. Laurell, S., and Tibbling, G.: An enzymatic fluorometric micromethod for the determination of glycerol. Clin. Chim. Acta, 13: 317 (1966).

18. Levitsky, L. L., Fisher, D. E., Paton, J. B., and de Lannoy, C. W.: Fasting plasma levels of glucose, acetoacetate, $\mathrm{D}$ - $\beta$-hydroxybutyrate, glycerol and lactate in the baboon infant: correlation with cerebral uptake of substrates and oxygen. Pediatr. Res., 11: 298 (1977).

19. Little, J. R., and Spitzer, J. J.: Uptake of ketone bodies by dog kidney in vivo. Am. J. Physiol., 221: 679 (1971).

20. Loomis, M. E.: An enzymatic fluorometric method for the determination of lactic acid in serum. J. Lab. Clin. Med., 57: 966 (1961).

21. Nieth, H., and Schollmeyer, P.: Substrate-utilization of the human kidney. Nature (Lond.), 206: 1244 (1966).

22. Opperman, W., Mehtalia, S. D., Sodero, E. C., Cole, H. S., and CameriniDavalos, R. A.: A sensitive micromethod for the simultaneous determination of insulin and growth hormone by double antibody precipitation. Clin. Biochem., 2: 341 (1969).

23. Owen, O. E., Felig, P., Morgan, A. P., Wahren, J., and Cahill, G. F.: Liver and kidney metabolism during prolonged starvation. J. Clin. Invest., 48: 574 (1969).

24. Paton, J. B., Fisher, D. E., Saba, T. M., and Behrman, R. E.: Measurement of liver blood flow in the infant monkey: comparison of methods. Biol. Neonate, 23: 1 (1973).

25. Persson, B.: Determination of plasma acetoacetate and D- $\beta$-hydroxybutyrate in newborn infants by an enzymatic fluorometric micromethod. Scand. J. Clin Lab. Invest., 25: 9 (1969).

26. Pogson, C. I. Longshaw, I. D., Roobol, A., Smith, S. A and Alleyne, G. A. O. Phosphoenolpyruvate carboxykinase and renal gluconeogenesis. In: $\mathbf{R}$. W.. Hanson, M. A., Mehlmar: Gluconeogenesis. (John Wiley \& Sons, New York. 1976).

27. Roxe, D. M., Schreiner, G. E., and Preuss, H. G.: Regulation of renal gluconeogenesis and ammoniagenesis by physiologic fuels. Am. J. Physiol., 225: 908 (1973).

28. Steiner, A. L., Goodman, A. D., and Treble, D. H.: Effect of metabolic acidosis on renal gluconeogenesis in vivo. Am. J. Physiol., 215: 211 (1968).

29. Tomisek, A. J., and Natelson, S.: Fluorometric assay of ultramicro quantities of glucose with Somogyi filtrate and hexokinase. Microchem. J., 19: 54 (1974).

30. Zorzoli, A., Turkenkopf, I. J., and Mueller, V. L.: Gluconeogenesis in developing rat kidney cortex. Biochem. J., 111: 181 (1969).

31. Presented in part at the Society for Pediatric Research, 1976.

32. The authors thank Jane Uehara, Lagrimas Munoz, Audrey Paton, and JoAnne Marcichow for their excellent technical assistance and Jean Zuk and Madeline Murphy for their superior secretarial support. Harry Levine and Robert Dulski provided useful statistical advice and computer analysis.

33. Requests for reprints should be addressed to: Lynne L. Levitsky, M.D., Department of Pediatrics, Michael Reese Hospital and Medical Center, 29th Street and Ellis Avenue, Chicago, Illinois 60616 (USA).

34. This research was supported in part by USPHS Grants HD08608 and HDI3138 as well as by the Michael Reese Research Institute.

35. Received for publication September 6, 1979.

36. Accepted for publication December 20, 1979. 